their difficulty, are flaws in the otherwise excellent treatment, and the same could be said of all the other exercises in the book. Anyone learning a technique needs to practise it to make sure he has learned it correctly. Any book intended for teaching, therefore, should contain many exercises graduated from the easy to the difficult. The second chapter is a discussion of the usual discrete distributions including the negative binomial, the logarithmic, Polya and the Borel-Tanner. Chapter 3 is on Markov Processes, the elementary theory being illustrated on the Ehrenfest model, gambler's ruin and recurrence times. Further theoretical development is on the reversed chain, the solution of the Kolmogorov equations and imbedding. Illustrations include birth and death processes, random walk, the Borel-Tanner process, the Polya process and queueing.

Professor Moran now turns to measure theory and chapters 4 through 9 see the development of probability theory relative to Euclidean space. Chapter $\mathbf{4}$ covers measure theorems and integration, chapter 5 random variables and continuous distributions, and chapter 6 the functional transform known as the characteristic function. The student will find these three chapters relatively hard after the first three chapters. Chapter 7, however, on continuous distributions, is comparatively easy. The eighth chapter covers sequences and sums, and chapter 9 the arithmetic of distributions and Brownian motion. The book is completed by the tenth chapter on the random walk.

Professor Moran says in his preface that he has designed the book to be read by honours students in their third year. I suggest that it could well be given before that and I plan to try. But anyway this is an excellent probability text and should be on the shelves of anyone teaching probability theory and its relation to statistics.

F. N. DAvid

\section{FUNCTION THEORY}

\section{Topics in the Theory of Functions of One Complex Variable}

By W. H. J. Fuchs. (Van Nostrand Mathematical Studies.) Pp. vi + 193. (Van Nostrand: Princeton, New Jersey and London, 1967.) $\$ 3.25 ; 30$ s. paperback.

THIs book brings together a variety of topics which might well find their place in an advanced third year or postgraduate course in function theory. All are important from the point of view of modern research and because the book is written very persuasively by a well known expert in the field it is sure to make many new friends for the subject. The approach is classical and concrete, exoept in the last chapter where the author gives us a glimpse of Sario and Chern's version of Nevanlinna's second fundamental theorem for analytic mappings between Riemann surfaces. For this purpose the exterior differential calculus and the Gauss-Bonnet formula are developed. This is preceded by an account of the first fundamental theorem derived from the Poisson-Jensen formula and the Hadamard representation of meromorphic functions of finite order. The author also obtains the representation of a function of bounded characteristic in the unit disk as the ratio of bounded functions.

The first three chapters are about subharmonic func. tions and their application, Schwarz's reflexion principle and the problem of Dirichlet. There follows a chapter on Mergelyan's work on the problem of weighted approximation of continuous functions by polynomials.

Lindelöf's principle and subordination lead to the theorem of Schottky with a good numerical estimate and the theorems of Picard. These are followed by three chapters on harmonic measure, extremal lengths and the transfinite diameter respectively.

The proofs are simple and elegant, so that the reader is never taxed unduly. In spite of, or perhaps because of, this, the book contains a very great deal of material, much of which is not available in other text books. Some of the results are given in the form of problems for the reader, usually with adequate hints.

There seem to be few mistakes. In theorem $9 \cdot 3 \mathrm{read}$

$$
\text { " }<\infty " \text { for " }=0 \text { ". }
$$

The references are embodied in the text and are sometimes a little sketchy, and there is no index or bibliography. But these are minor criticisms of what I find a most rewarding book.

W. K. Hayman

\section{SUPRAMOLECULAR STRUCTURE}

\section{Supramolecular Structure in Fibers}

(The 25th Anniversary Conference of the Fiber Society, Boston, Mass., Sept. 21-23, 1966. Journal of Polymer Science, Part C, Polymer Symposia, No. 20.) Edited by Paul H. Lindenmeyer. Pp. vii + 286. (Interscience (Wiley): New York and London, 1967.) 30s. net.

THrs most interesting collection of papers on supramolecular structure serves to publish the proceedings of the 25th anniversary of the Fiber Society in Boston, September, 1966. A wide range of fibre scientists were invited to make contributions and each paper was given by an acknowledged expert in his own field. There is a tendency at the present time to publish collections of papers delivered at specialist symposia and these may possibly be producing a range of literature which is only of interest to a very narrow field of workers and may tend to give a repetitive mass of published literature. This publication cannot be included in this field-it is an authoritative publication, produced at the highest level, and should form part of the literature of any fibre science library.

It would be invidious to select any one paper for special comment, and its authors are fully international in character. The X-ray crystallographic aspects of modern fibre erystallography are dealt with in the first three papers-synthetic polymers, optical diffraction techniques in structure interpretation, and X-ray diffraction and electron microscopy studies of keratin fibres. In this latter field there are also two papers from Australia on the mechanical properties and high sulphur proteins of keratin. Histochemical studies using electron microscopy are also dealt with in detail.

The field of man-made fibres deals with spherulitic crystallization, uniaxial stretching and anisotropy, molecular orientation and the relation of fibre structure and length variations. A molecular theory of polymer chain folding is adduced and a physical study of rates of deformation of crystalline polymers is made. Finally the structural mechanies of fibres is described, and an interesting paper given by R. J. Samuels at the regular meeting of the Fibre Society in North Carolina, May 1967, is included. As recorded in the preface, the paper "Spherulitic Structure, Deformation Morphology and Mechanical Properties of Isotactic Polypropylene Fibres" was added because of its pertinence to the subject.

This publication is an important addition, even to the present extensive specialist literature on fibre science.

F. HAPPEY

\section{MODERN FIBRE SCIENCE}

\section{Man-Made Fibers}

Science and Technology, Vol. 1. Edited by H. F. Mark, S. M. Atlas and E. Cernia. Pp. xi+432. (Interscience (Wiley): New York and London, 1967.) $165 s$.

BY 1970 the world production of synthetic fibres will equal what was the world consumption of cotton and 